\title{
Carmina Figurata e a Teoria da Imagem Carolíngia. Contributos para uma Reflexão sobre a Relação Texto-Imagem
}

Tese de Doutoramento em História da Arte, área de especialidade em Teoria da Arte, apresentada à FCSH-UNL, Julho de 2016. Orientação das Professoras Doutoras Joana Cunha Leal e Maria Adelaide Miranda

\section{Maria Coutinho}

\section{(2) OpenEdition}

\section{Journals}

\section{Edição electrónica}

URL: http://journals.openedition.org/medievalista/1393

DOI: 10.4000/medievalista.1393

ISSN: 1646-740X

Editora

Instituto de Estudos Medievais - FCSH-UNL

\section{Refêrencia eletrónica}

Maria Coutinho, "Carmina Figurata e a Teoria da Imagem Carolíngia. Contributos para uma Reflexão sobre a Relação Texto-Imagem », Medievalista [Online], 22 | 2017, posto online no dia 01 dezembro 2017, consultado o 23 setembro 2020. URL : http://journals.openedition.org/medievalista/1393 ; DOI : https://doi.org/10.4000/medievalista.1393

\section{(c) (7) (5)}

Mediavalista está licenciado com uma Licença Creative Commons - Atribuição-NãoComercial 4.0 Internacional. 
Título / Title: Apresentação de Tese / Thesis presentation: Carmina Figurata e a Teoria da Imagem Carolíngia. Contributos para uma Reflexão sobre a Relação Texto-Imagem. Tese de Doutoramento em História da Arte, área de especialidade em Teoria da Arte, apresentada à FCSH-UNL, Julho de 2016. Orientação das Professoras Doutoras Joana Cunha Leal e Maria Adelaide Miranda

Autor(es) / Author(s): Maria Coutinho

Universidade / University: Universidade Nova de Lisboa

Faculdade e Departamento / Unidade de Investigação - Faculty and Department /

Research Center: Faculdade de Ciências Sociais e Humanas / Instituto de Estudos

Medievais; Instituto de História da Arte

Código Postal: 1269-061

Cidade / City: Lisboa

País / Country: Portugal

Email Institucional / Institutional email: maria1coutinho@gmail.com

Fonte: Medievalista [Em linha]. Direc. Bernardo Vasconcelos e Sousa. Lisboa: IEM.

Disponível em:

http://www2.fcsh.unl.pt/iem/medievalista/MEDIEVALISTA22/coutinho2213.html

ISSN: 1646-740X

Data recepção do artigo / Received for publication: 1 de Maio de 2017 
Carmina Figurata e a Teoria da Imagem Carolíngia. Contributos para uma Reflexão sobre a Relação TextoImagem. Tese de Doutoramento em História da Arte, área de especialidade em Teoria da Arte, apresentada à FCSH-UNL, Julho de 2016. Orientação das Professoras Doutoras Joana Cunha Leal e Maria Adelaide Miranda

Maria Coutinho

Partindo dos poemas figurados (carmina figurata) elaborados entre a década de oitenta do século VIII e c. 814 por autores como Alcuíno, Josefo Escoto, Teodulfo e Rábano Mauro, analisa-se este corpus dando especial relevo ao contexto e às condições da sua produção no âmbito da corte carolíngia ${ }^{1}$.

Com uma origem que possivelmente remonta à Antiguidade Clássica, os poemas figurados materializam-se numa indivisível associação entre texto e imagem. Esta fusão dialéctica na qual a imagem molda o texto e a escrita dá corpo à imagem conheceu um significativo incremento numa conjuntura em que as elites letradas carolíngias acompanhavam a chamada "querela das imagens" que tinha lugar em Bizâncio. Esta valorização e multiplicação dos poemas figurados inseriu-se num projecto político indissociável das condições políticas, sociais, culturais e religiosas da monarquia carolíngia.

Tendo presente que a dimensão literária dos poemas figurados estava já amplamente estudada, o encontro com as obras desencadeou, desde logo, um interesse - que

\footnotetext{
${ }^{1}$ A Tese de Doutoramento aqui apresentada pode ser consultada no Repositório da Universidade Nova. Disponível em https://run.unl.pt/handle/10362/19090?locale=en
}

Medievalista online $\mathrm{N}^{\circ} 22$ | Julho - Dezembro 2017 ( ) IEM - Instituto de Estudos Medievais 2 www2.fcsh.unl.pt/iem/medievalista 
justificou a inscrição da tese na especialidade de Teoria da Arte, do Doutoramento em História da Arte - em averiguar o lugar da imagem e o reconhecimento das suas componentes figurativas e pictóricas, para não dizer estritamente plásticas. Esse interesse na centralidade da imagem consolidou-se e ganhou corpo como interrogação estruturante à medida que se desenvolvia o trabalho de pesquisa e na sequência do confronto reiterado com dois modelos de interpretação predominantes dos carmina figurata, discutidos, grosso modo, na Parte I e na Parte II da dissertação. O primeiro, tende a justificar a presença da imagem como derivação de processos métricos, fundamentados na sua evidente e legítima, mas não exclusiva, vocação poética. O segundo, secundariza a imagem em função de uma cultura escrita e concebe-a como testemunho de uma vivência da religiosidade, própria dos carolíngios, centrada no significado, onde se enfatiza a primazia da palavra, directamente ligada às Sagradas Escrituras.

De um ponto de vista metodológico estes dois modelos de interpretação implicam os seguintes pressupostos: (i) os poemas figurados seriam reflexo de uma determinada vivência social, cultural e religiosa, à qual caberia um espírito de tempo próprio, uniforme e convergente; (ii) seria reconhecida aos carmina figurata a capacidade de reflectir ou expor esse mesmo contexto, mas não a de agir com e transformar as condições históricas; (iii) os debates teológicos que encetam, ou com que dialogam, seriam determinantes na composição da imagem e sua função primeira, se não mesmo única; (iv) a sua alocação - aparentemente natural - num território de disputa, isto é, de altercação entre o valor do texto e o da imagem, reconhecendo ao primeiro predomínio e controle sobre o segundo.

É assim que, dimanando do diálogo historiográfico, se materializaram as seguintes indagações que deram lugar ao desenvolvimento da tese: Podem os processos métricos dos carmina figurata, decisivos na formulação da imagem, ser a única justificação para a sua componente imagética? Confirmam os poemas figurados apenas uma vivência da espiritualidade centrada no entendimento carolíngio das Escrituras? São prova de uma cultura da escrita que estabeleceria a imagem como inferior ao texto, convergente com a que os francos proclamam oficialmente na sequência do debate iconoclasta? Ou haveria elementos na redacção, circulação e recepção das obras e dos discursos sobre imagem

Medievalista online № 22 | Julho - Dezembro 2017 ๑ IEM - Instituto de Estudos Medievais 3 www2.fcsh.unl.pt/iem/medievalista 
que permitissem explorar um reconhecimento coevo da presença da imagem enquanto tal?

Informada por reflexões teóricas contemporâneas, acolhendo delas a sua herança múltipla, e situando-se num lugar que não pretendeu dirimir esse ponto de partida - até porque falar em imagem ou na "sua presença enquanto tal” é uma operação que projecta um entendimento já de si situado e condicionado - a dissertação desenvolveu as questões expostas. A natureza da pesquisa exigiu um trabalho empírico e analítico assinalável, de forte pendor histórico, aliado às motivações teóricas e críticas. Tal conduziu a uma meditação prolongada sobre a estrutura da tese, acompanhando os pressupostos historiográficos dominantes enunciados, adoptando-se uma forma tripartida. Partiu-se do estudo dos poemas figurados, abriu-se o escopo à atitude carolíngia sobre imagem (pela mão dos mesmos autores dos poemas) e, finalmente, alargou-se a reflexão à especulação teórica em torno das relações entre texto e imagem. Transversais a toda a dissertação e sem correspondência directa com a sua repartição são três aspectos basilares: a produção ou composição dos poemas, a sua circulação na época e a recepção posterior. A investigação aqui em debate assumiu, pois, a multiplicidade destas e de outras linhas de reflexão como um desafio constitutivo do seu desenvolvimento e como parte da sua metodologia, ainda que lidando de modo operativo com categorias temporais e espaciais balizadas.

Pode dizer-se, portanto, que a análise e a discussão da relação entre a escrita e a imagem no contexto histórico referido, mas também muito para além dele, constitui o objecto central desta dissertação realizada no âmbito conceptual, metodológico e epistemológico da Teoria da Arte.

Assim, depois de um Preâmbulo em que se define o objecto de estudo e as fontes sobre as quais este se irá debruçar, a Parte I apresenta um primeiro capítulo que é como que uma introdução “Acerca da origem e genealogia da poesia figurada”, desde os technopaegnia gregos até aos autores romanos e do Tardo-Antigo que cultivaram o género dos carmina figurata. O segundo capítulo incide sobre o tema central, os “Carmina Figurata carolíngios (c. 780 - c. 814)”. Destacam-se cinco subcapítulos cuja enunciação reflecte uma análise que procura interpretar os poemas e a sua lógica muito 
para além de uma perspectiva exclusivamente formal ou mesmo contextual. É o que resulta da "Afirmação de um projecto político, cultural e religioso” (ponto 2.1.), dos “Panegíricos a Carlos Magno” (ponto 2.2.), do "Ciclo em honra e louvor da Santa Cruz” (ponto 2.3.), da abordagem do “In honorem Sanctae Crucis de Rábano Mauro” (ponto 2.4.) e da compreensão da "Poesia figurada à luz da economia do dom” (ponto 2.5.).

O estudo de outras composições poéticas e visuais anteriores às medievais e dos processos de criação e circulação dos poemas figurados carolíngios - com o propósito de interrogar o primeiro dos dois modelos de estudo predominantes acima indicados permitiu apontar que, não obstante a plausibilidade de contactos ou retomas de outros exemplos anteriores, a hipótese de que há uma evolução de género não tem validade empírica ou teórica, e a afirmação das condições figurativas destes poemas a partir da derivação de dispositivos literários revela-se insuficiente para atentar às suas especificidades. Ao mesmo tempo que esta hipótese valoriza a dimensão literária, enfraquece a relevância das obras enquanto objectos plásticos, que é, afinal, incontornável. E é-o, desde logo, no processo de composição a partir da atribuição de um só folio para cada poema; da definição gráfica de um espaço no qual se enquadrará a escrita; da delineação da forma que antecede a redacção do poema; do uso da cor e de elementos figurativos como a moldura; da existência de elementos plásticos, como os pigmentos e a alternância de gamas cromáticas; do tipo de letra que se diferencia no seio das imagens, e, evidentemente, do desenho das próprias figuras. Do mesmo modo, as cores, tipos de letras, ou mesmo as formas desenhadas são abordadas na redacção de alguns poemas apelando à sua visualização (num gesto surpreendentemente meta ou auto-reflexivo). E, na sequência das advertências que Rábano Mauro deixa no Prólogo do In Honorem Sactae Crucis - a sua obra de vinte e oito poemas figurados - ou da circulação e subsequente cópia destes manuscritos, identifica-se uma consciência do uso da imagem e respectivas componentes pictóricas que não se satisfaz em qualquer noção alargada de texto.

Também a análise dos processos que precedem, acompanham e são mobilizados pela poesia figurada carolíngia no espaço da sua composição e circulação coetânea, a par da pesquisa de nexos materiais - como o funcionamento social e político, os códigos institucionais, entre os quais os do dom, e o projecto governativo carolíngio -, expõem a 
existência de uma acção mútua e dialógica na construção das representações régias e dos próprios autores. Para além da sua vocação espiritual, o papel político destas composições é determinante e exibe, com contundência, a sua capacidade para gerar efeitos e agir. No entanto, é esse mesmo trabalho de discussão teológica conduzido nos poemas que fundamentou o confronto com os argumentos da querela das imagens bizantina que interpela a corte franca neste período.

A Parte II abre igualmente com um Preâmbulo sobre "as razões pelas quais os carmina figurata foram objecto de estudo privilegiado da Literatura” (pág. 150), debatendo essas razões e os seus limites, a partir dos autores que, neste campo, se dedicaram ao tema. Procura-se, aqui, acompanhar o segundo modelo interpretativo dominante que considera a presença da imagem uma confirmação da importância da cultura escrita na corte franca. O terceiro capítulo alarga a perspectiva de análise em função d' “A querela iconoclasta e a reacção dos francos", com três pontos: "Interdição das imagens sagradas” (3.1.), “Em defesa dos Santos Ícones” (3.2.) e "Resposta carolíngia ao debate das imagens” (3.3.), colocando, em definitivo, a tónica também na interpretação do lugar e do papel da imagem. O quarto capítulo, intitulado “A(s) teoria(s) da imagem carolíngia”, constitui a chave interpretativa para uma compreensão histórica, quer dizer social e política, da função, da utilidade (e inutilidade) e do “culto” prestados aos carmina figurata no período carolíngio e postas em prática pelas suas elites políticas e culturais letradas. Analisam-se os "Libri Carolini e a supremacia da escrita" (ponto 4.1.), a “Teoria da corte, 'Documento de Estado’” (ponto 4.2.), o tópico “’Ad bonosum', vale o sinal da escrita mais do que a pintura?” (ponto 4.3.), culminando em "Imago, figura e pictura, reabilitar o 'ver'” (ponto 4.4.). Ou seja, propõe-se uma breve análise de três textos fundamentais: os Libri Carolini (tratado franco de resposta ao iconoclasmo bizantino de c. 794); um poema onde Rábano Mauro afirmaria a superioridade da escrita "Ad Bonosum" 38 (escrito em c. de 810) e o antes indicado In Honorem Sanctae Crucis, também de Rábano Mauro.

Deste modo, a Parte II descerra a investigação ao que aqui se designou como teoria da imagem carolíngia, ou seja, a posição oficial da corte sobre o debate do iconoclasmo. O investimento da investigação nos argumentos teológicos de ambas as facções teve em vista alcançar um conhecimento mais dominado sobre as suas proximidades e 
diferenças, a fim de identificar que entendimento conceptual de imagem poderia estar em causa. E ainda para validar se, no caso dos francos, este se adequaria ao que a historiografia propõe como sendo um reconhecimento liminar da superioridade da Palavra, tal como da palavra, e a um esbatimento da dimensão material da imagem em detrimento da sua significação. Tratar-se-ia de uma única teoria que dava conta do pensamento unificado da comunidade carolíngia, confirmado nos poemas de Rábano Mauro? Com o comentário a alguns dos argumentos é proposto que em causa não estaria uma oposição absoluta entre imagem e Palavra, onde aquela se submeteria a esta, mas a impossibilidade da sua equiparação. No transcender de quadros interpretativos de dominação desdobrou-se, enfim, a noção de imagem.

A querela das imagens foi tratada tendo presente alguns dos interesses políticos, territoriais, económicos, administrativos e religiosos dos três centros envolvidos (corte franca, papado e império bizantino). Neste sentido, assinalou-se, seguindo a bibliografia, que o debate não é independente das conveniências de cada uma das partes e da sua concepção de poder. A discussão sobre imagem reflecte os interesses dos focos de autoridade. Os argumentos dos Libri Carolini, o poema Ad Bonosum 38 e a área vocabular do campo da imagética ou da composição plástica no In honorem de Rábano Mauro sugerem a provável inexistência de uma visão harmonizada e a plausível concomitância não de um, mas de diversos entendimentos sobre o significado de imagem, a que não são alheias as circunstâncias e subjectivações de cada autor ou de cada centro de poder.

Três linhas meditativas emergiram desta inquirição:

Em primeiro lugar não parece haver razões objectivas que permitam mitigar a visualidade das imagens nos poemas figurados. Assim, não fará sentido procurar neles uma comprovação da teoria da imagem carolíngia. Depois, esta mesma teoria talvez não se afigure como una, antes expondo uma riqueza interpretativa que importa valorizar. Por fim, também não parece estar em causa uma distribuição antinómica entre Palavra e Imagem. Com efeito, esta oposição tem os seus fundamentos históricos que respondem a distintas causas, o que conduziu à Parte III da tese. 
A Parte III constitui como que uma conclusão, apresentada como capítulo cinco, sobre a “Recepção dos carmina figurata e o debate texto-imagem”, enfatizando a vertente da Teoria da Arte na qual se insere a dissertação. Em termos de problemática, o destaque é dado à reflexão sobre a "Antinomia entre texto e imagem e o pensamento logocêntrico" (ponto 5.2.) e ao estabelecimento de um "Paradigma da visualidade; paradoxo (ir)resolúvel” (ponto 5.2.).

A recepção moderna dos poemas figurados torna-os palco da disputa entre pintura e poesia com rastros que se disseminam até à contemporaneidade. Esta recepção introduz avaliações judicativas acerca das qualidades poéticas da poesia figurada, predicadas em preconceitos que fundamentam a derivação da imagem a partir da escrita. Outras questões se cruzarão com estas, de teor teológico, filosófico, institucional e, mais tarde, disciplinar, o que não só alimentará a oposição entre texto e imagem ou entre objectos poéticos e artísticos, como aprofundará a distinção entre forma e conteúdo, interior e exterior das imagens. Torna-se a imagem indissociável do seu significado e a sua presença é vista como referência, no caso, confirmação da sua função religiosa, o que condicionará o reconhecimento do que nela permanece figurativo e transcende esse significado. Foi justamente essa visão dicotómica que se procurou problematizar ao longo deste trabalho, procurando iluminar a sua raiz histórica e propor uma interpretação que prestasse justiça à força da imagem e à sua polissemia.

A questão teórico-metodológica central que se procura deixar em aberto, ensaiando uma incompleta e deliberadamente provisória conclusão é a de “Como, então, lidar com o problema 'texto e imagem'? Com as relações entre a Literatura e a História da Arte, com objectos heterogéneos, múltiplos na sua compleição, como os poemas figurados?” (pág. 286). Em resumo, a resposta que resulta das três centenas de páginas de argumentação, é considerar que “uma solução como ‘texto-imagem’ [que acolha ambos os componentes sem os submeter a dinâmicas de autoridade e precedência] permite interromper narrativas de dominação. Permite afrontar o projecto de os opor radicalmente como campos opostos, permite afrouxar as tensões que justificam a prevalência de um sobre o outro. Permite que à imagem seja reconhecida a sua existência no campo da visualidade, antes ainda das dinâmicas teológicas, institucionais, culturais e disciplinares de apropriação de forças. E permite, por fim, pensá-la, à 
imagem, em termos equânimes na composição, de modo a que a sua presença tenha um justo reconhecimento, como advertiu o próprio Rábano Mauro.” (pág. 288).

Em anexo são publicados vários documentos, entre os quais os poemas-imagens do corpus, imprescindíveis para uma cabal e articulada percepção da análise e das interpretações desenvolvidas no corpo principal da tese.

\section{COMO CITAR ESTE ARTIGO}

\section{Referência electrónica:}

COUTINHO, Maria - "Carmina Figurata e a Teoria da Imagem Carolíngia.

Contributos para uma Reflexão sobre a Relação Texto-Imagem. Tese de Doutoramento em História da Arte, área de especialidade em Teoria da Arte, apresentada à FCSHUNL, Julho de 2016. Orientação das Professoras Doutoras Joana Cunha Leal e Maria Adelaide Miranda”. Medievalista 22 (Julho-Dezembro 2017). [Em linha] [Consultado dd.mm.aaaa]. Disponível em http://www2.fcsh.unl.pt/iem/medievalista/MEDIEVALISTA22/coutinho2213.html ISSN 1646-740X.

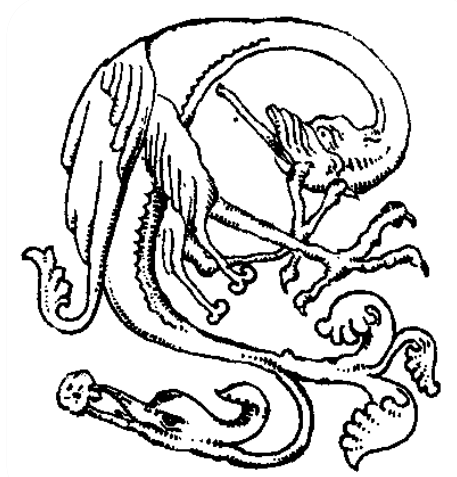

